\title{
Hamlet dialoga con Ofelia
}

Federico PATÁN

Universidad Nacional Autónoma de México

La traducción literaria no es sólo cuestión de idiomas, es cuestión de idiomas impregnados de cultura. Quien no comprenda verdad así de sencilla, mal traductor será por mucho que suponga dominar una lengua en lo gramatical. Pero es necesaria una ampliación del concepto. La traducción significa ante todo el encuentro de dos culturas, aquella del texto por verterse a la lengua de llegada y aquella perteneciente a ésta. Entre ambas ha de establecerse un diálogo de componendas, mediante el cual procuran allanarse los desacuerdos existentes, que serán mayores o menores según el distanciamiento que entre ambas culturas haya ido estableciendo el transcurrir del tiempo.

Ahora bien, toda cultura es un encadenamiento a la vez que una fusión de los momentos históricos transcurridos, los cuales fueron dejando su huella sobre la naturaleza de dicha cultura. Pensemos lo siguiente: cuando decimos que un negocio "va con velas desplegadas" estamos recurriendo a una imagen que, sin duda, nos viene de antiguo y que no expresa ya una realidad existente. Sin embargo, en nosotros vive ese ayer y todos entendemos su significado metafórico, pues se ha injertado en nuestro idioma como expresión tópica. En la cultura que nos haya tocado vivir encontramos muchos aspectos que nos son ajenos porque no pertenecen ya a lo cotidiano. Este ajenamiento crece si la comparación se da entre dos culturas distintas. Desde luego, cuando las dos culturas en relación mediante un texto pertenecen a la misma época, mucho se alivia la tarea del traductor. Según se alejan en el tiempo las dificultades crecen, pues se da un distanciamiento creciente entre los hábitos lingüísticos y culturales de ese pasado y aquellos del hoy. Hábitos que transmiten toda una visión del mundo, toda una manera de vivirlo.

Así con Hamlet: pertenece a la cultura isabelina y cuatrocientos años separan su composición de nuestros tiempos de lectura, esos cuatro siglos han dado a la obra categoría de clásico, queriéndose decir con ello 
que ha superado la indiferencia de generaciones de lectores pues, a cada una de ellas, le ofrece algo que de no existir empobrecería a la cultura receptora. Aquí entra ya un comentario: Hamlet es clásico pero no lo fue en su época. Una perogrullada, claro. Los clásicos adquieren esa cualidad con el transcurso del tiempo. Pero volvamos a la situación descrita: fue obra recibida como una más de tantas que por entonces se montaban. Así, de haberse dado en ese ayer interés en traducirla quien lo hiciera no la hubiera abordado como texto clásico. Hoy día es inevitable hacerlo.

Lo anterior impone ya al traductor la obligación de ciertas decisiones, como son las de vocabulario, las de estilo y las de tono. Sucede que las palabras tienden a dejar significados en el pasado e ir obteniendo otros nuevos. Cuando un texto, como Hamlet, nos mira desde su escritura en 1601, parte de lo que dice conserva vigencia de sentido, pero parte del sentido se nos ha extraviado, para volverse campo de actividad de los especialistas. Así, en esà obra doubt tiene en una de las ocasiones el sentido de "sospecha" y no de "duda", lo cual influye bastante en la comprensión del verso donde se incluye la palabra. O bien four, que aparte de su significado actual tenía aquel otro de "varios", para no hablar de los términos ya desaparecidos porque describen objetos o costumbres de la época. De esta manera, progress significaba un viaje oficial, sobre todo si lo hacía un monarca. Entonces, cuando Hamlet habla de cómo un gusano progresa por las tripas de un pez, la intención irónica debe ser percibida por el traductor, quien por algún medio ha de transmitirla al lector. De esta manera, los clásicos pueden estar llenos de trampas creadas por el incontenible transcurrir del tiempo, que un buen traductor ha de aceptar como un deleite, aquel del reto a su capacidad de traslado.

En cuanto a estilo, necesario es comprender que Hamlet no sólo transcurre en un pasado ya remoto, sino en la corte danesa. Pero, la cuestión se complica, una corte danesa necesariamente influida por la experiencia de Shakespeare; es decir, por los hábitos palaciegos de la corte isabelina, como lo demuestra el mencionado progress. Si tradujéramos el "I hear him coming" de Polonio por un "Aguas, que ahí viene", como lectores no lo aceptaríamos porque rompería nuestra imagen de lo que una corte es. Lo aceptaríamos, sí, como parte de alguna farsa, mas no como expresión directa del original. Compárese con tres de las versiones dadas a este fragmento: "Oigo que viene", "Lo oigo venir" y "Ahí viene".

Por tono quiero decir el sabor de la expresión, en el sentido de si hay melancolía, tristeza, amargura, buen humor, burla, ironía, sarcasmo, alguna combinación de todo esto o la presencia de otras posibilidades que no haya mencionado. Vuelvo a Hamlet. Su monólogo de "Ser o no ser" 
expresa, junto a varias substancias más, un pesimismo enorme respecto de la vida. Si lo tradujéramos llevándolo por los caminos de una ligereza de expresión ajena al tono, traicionaríamos el sentido profundo de lo expresado. Todo lo anterior viene a derivar en el motivo de estos comentarios. Si algo predomina en Hamlet es la ironía. El protagonista se defiende de las ofensas del mundo recurriendo sin cesar a esa forma de ataque, el cual aplica con especial denuedo a quienes son sus enemigos. Cuando Hamlet dialoga con Horacio se da la ironía, mas no contra este segundo sino como subrayado a la condición de la humanidad. Cuando Hamlet dialoga con Polonio o con Osric descarga su veneno directamente contra el personaje.

Así llegamos a Ofelia. En la obra se le da, relativamente, poca presencia. Esa presencia queda opacada por aquella de los otros personajes centrales. Pocos son sus diálogos y pocas sus oportunidades de expresarse. Quizá las mayores cuando, loca ya, canta sus desgracias. Tuvo relaciones amorosas con Hamlet. Si llegaron a algo más que un intercambio de palabras o una aceptación de cortejo es difícil saberlo por la obra. Quizás alcanzaran la condición de amantes, lectura que Kenneth Branagh hizo explícita en su película de 1996. Lo cierto es que Hamlet manifiesta a lo largo de la obra su desilusión respecto a la hija de Polonio, acaso derivada de saberla demasiado obediente a los mandatos del padre, demasiado situada en el campo enemigo. Por tanto, el príncipe suele mostrarse duro con ella, y no escatima la ironía en los diálogos que sostiene con la joven. Y sucede que algunos de ellos vienen teñidos con subterráneas referencias sexuales, cuyo propósito es herir la sensibilidad de la muchacha. Uno de tales casos se da en la escena segunda del acto III, cuando la representación de la obra llamada por Hamlet The Mousetrap. Es decir, La ratonera.

Pues bien, veamos de qué manera se enfrentaron a esas subterráneas puyas tres traductores. Los elegidos han sido Luis Astrana Marín, español; Joaquín Gutiérrez, costarricense, y Enriqueta González Padilla, mexicana. De propósito elegí traductores pertenecientes a tres culturas distintas. Esto permitirá ver si las diferencias geográficas insertan en el texto de llegada algunas cuestiones de orden lingüístico y de qué manera se han enfrentado los traductores al párrafo en cuestión. Por otro lado, las traducciones pertenecen a tres épocas distintas, lo cual también habrá ejercido su influencia en el abordaje del diálogo que nos interesa.

La traducción más antigua es aquella de Luis Astrana Marín (18891959). Autor de estudios sobre Lope de Vega, Quevedo y Cervantes, también fue traductor. Se han criticado bastante sus versiones de Shakespeare, 
y motivos hay para permitírselo. No le quitemos el mérito, sin embargo, de haber sido el primero en traducir al español la obra íntegra del isabelino. Mi edición de dicha obra es la séptima y apareció en 1945. Esto permite situar la primera en la década de los treinta y darnos una fecha aproximada de producción. No tengo la menor idea de cómo llegó a mis manos la traducción de Joaquín Gutiérrez. Sin duda la compré en alguna librería de viejo, llevado por el hábito de interesarme en las versiones que encuentro de la obra shakesperiana. Sé, por los datos de edición, que el libro lo avaló la Editorial Universidad Estatal a Distancia y que se editó en 1982. En cuanto a González Padilla, su traducción es parte del Proyecto Shakespeare de la UNAM y apareció el año 2000 como volumen 87 de Nuestros Clásicos. En el caso de Enriqueta, tuvo la colaboración de Alejandra Luna Guzmán y de Adrián Muñoz García.

Digamos, brevemente, que los tres traductores estaban bien preparados para la empresa acometida. El extenso prólogo de Astrana Marín hace ver cuántas lecturas de apoyo, cuántas investigaciones se cumplieron como etapa preparatoria de la traducción. He dicho que fue un estudioso de Lope, Quevedo y Cervantes. No dudo que el conocimiento de estos autores le dio herramientas para resolver varios problemas que la traducción de Shakespeare le habrá presentado. En cuanto a Joaquín Gutiérrez, no tengo mayor noticias que el libro mismo. Pero en el prólogo encuentro que Gutiérrez fue autor de una traducción del Rey Lear y descubro un estudioso al tanto de mucha minucia shakesperiana, lo cual me hace pensar en un hombre bien preparado para la empresa. Además, lo confiesa al explicar su método de trabajo, apoyó su tarea consultando siete versiones al español del Hamlet y al cotejar, lo cito, "nos dimos cuenta de que numerosos párrafos son interpretados de manera diversa. En esos casos nos atuvimos, naturalmente, a la interpretación que nos pareció más adecuada" (Gutiérrez, XXIII). En cuanto a González Padilla, mucho de su vida como profesora universitaria lo ha dedicado a Shakespeare y, además, fue la creadora del Proyecto Shakespeare, sigue dirigiéndolo y a la fecha ha publicado su traducción de unas quince obras del dramaturgo.

Situémonos en Hamlet. Obligado por el fantasma de su padre a vengarlo, el protagonista titubea, en parte dándose como razón la insuficiencia de pruebas en contra de Claudio, el posible asesino. Entonces, aprovechando la presencia de una compañía teatral, monta una tragedia llamada The Mousetrap, modificación de otra titulada El asesinato de Gonzago, según Hamlet de procedencia italiana, si bien no ha podido comprobarse la existencia de ese texto. Todos los personajes importantes 
de la corte asisten a la representación como público, entre ellos Polonio, quien fue actor aficionado en su juventud. Interrogado por Hamlet, confiesa haber hecho el papel de Julio César y haber sido muerto por Bruto en el Capitolio. A lo cual el príncipe comenta en versión de Astrana Marín: "¡Valiente brutalidad matar a tan distinguido compañero!", donde poco trasmina de la ironía que el original manifiesta. Voy a Gutiérrez, quien pone en boca de Hamlet este comentario: "Bien bruto habría de ser para matar allí a un becerro ya decapitado", que se acerca más al juego de burla presente en el texto inglés. Tercera versión, de González Padilla: "Valiente brutalidad, matar ahí a tan distinguido buey", asimismo más cercana a la ironía original. Habremos de notar que "bruto" o "brutalidad" aparece en las tres versiones, apuntando a uno de los juegos de palabras ofrecidos por Shakespeare. Mas un segundo juego ha quedado fuera de dos de las traducciones y aparece sesgada en la tercera. Cito ahora del inglés: "It was a brute part of him to kill so capital a calf there", donde "brute" y "capital" hacen referencia a "Brutus" y "Capitol", a la vez que "calf" recuerda los sacrificios rituales. El "distinguido compañero" de Astrana Marín desvirtúa por completo la intención malévola del original. "Becerro ya decapitado" procura mediante esta palabra última referirse a Capitolio. En cuanto a "distinguido buey" es una especie de oxímoron que en la palabra "buey" incluye el desdén de Hamlet por Polonio, más dejando fuera el juego de palabras. Sabemos que los juegos de palabras son harto espinosos en la traducción. Acaso pudiera verterse el trozo así: "Fue una brutalidad de su parte el matar allí a un becerro tan capital".

A continuación el público se acomoda y la reina invita al hijo para que se ponga a su lado. Este responde, yendo hacia Ofelia: "He aquí un imán más atractivo" (Astrana Marín), "por aquí veo un metal de mayor magnetismo" (Gutiérrez) y "aquí hay un imán más atractivo", donde se percibe, pese a las ligeras variantes, que el original no plantea problemas graves. Ya está Hamlet junto a Ofelia y pregunta: "Señora: ¿me permitís reposar en vuestra falda?" (Astrana Marín), o bien "Señora ipuedo tenderme en tu regazo?" (Gutiérrez) o bien "Señora, ¿me permitís recostarme en vuestro regazo?" (Gonzáles Padilla), donde el príncipe inicia ya su hostigamiento sexual. El término de trato es igual en los tres casos: el de "señora", pero sucede que en Gutiérrez viene a continuación un tuteo, y esa decisión nos plantea sin más un problema: ¿Hasta dónde es permisible? Según el prólogo, el traductor opta por el tuteo cuando "el 'superior' se dirige al 'inferior' o 'cuando hablan iguales entre sí' " (Gutiérrez, XXII). La decisión es personal, acaso fundamentada en los estudios sobre la época, pero no se sostiene textualmente. Shakespeare es muy claro al 
respecto, y mediante el "thee" o el "thou" significa una condición de tuteo, la cual no veo presente en la escena que nos ocupa. Por otro lado, el "señora" que antecede la pregunta lleva a eliminar la idea de un tuteo, como a eliminarla lleva la propia situación que se está viviendo.

"Regazo" es mejor palabra para adelantar lo que viene a continuación, pues Hamlet aclara: "Quiero decir reposar la cabeza en vuestra falda" (Astrana Marín), "Quiero decir, mi cabeza en tu falda" (Gutiérrez) y "Quiero decir, reclinar la cabeza" (González Padilla). Esta última propuesta resulta débil por insuficiente: no hace la debida conexión entre esa inclinación y el regazo de la joven Ofelia. Véase que el príncipe ha pasado de "regazo" a "falda", suavizando entonces la intención oculta de su pedido, que no por oculta escapa a la percepción de Ofelia. Esto desemboca en uno de los puntos clave del diálogo, cuando Hamlet pregunta: “¿Pensáis que quería decir alguna cosa fea?” (Astrana Marín), “Pensaste que mi pregunta era impúdica?” (Gutiérrez) y “¿Pensáis que quería ofenderos?" (González Padilla). Es obvio cómo las tres versiones procuran entregar el sentido del original, siendo la más apegada a éste la de Gutiérrez porque introduce el término "impúdico", mucho más cercano a Shakespeare que "cosa fea" u "ofenderos". "Ofender" se puede de maneras muy diversas, "cosa fea" insinúa ya la posibilidad de un algo fuera de la conducta esperable de un príncipe e "impúdico" nos lleva con mayor claridad a terrenos sexuales, donde muy profundamente se encuentra anclado el original.

Conviene examinar lo dicho por Hamlet en inglés. Helo aquí: "Do you think I meant country matters?", donde la palabra "country" es la clave de todo. Surge una pregunta: ¿por qué lo campirano habría de ser ofensivo? ¿Por la escasez de modales refinados que pudiera darse entre los campesinos? Acaso, si nuestra lectura de "country" es contemporánea. Mas si dicha lectura la situamos en época de Shakespeare, venimos a enterarnos que por aquel entonces "country matters" significaba "hacer el amor", y no dejaron de emplear la idea otros dramaturgos, como Thomas Dekker (1570?-1632) en Westward Ho. Así pues, lo que el príncipe pregunta es, en versión aproximada, “¿Creísteis que hablaba de hacer el amor?" Pero esto aún no alcanzaría la plenitud de intención que el original guarda porque, me hace ver Harold Jenkins en su edición crítica del Hamlet, la sílaba primera de la palabra "country" recordaba por sonido a "cunt", el órgano sexual femenino. Aquí, desde luego, el juego lingüístico parece irresoluble y, avergonzado, el traductor iría a una nota explicativa. A no ser que lograra una variante alejada de la fidelidad gramatical pero cercana al significado. Ofelia, cauta, responde "No pienso nada, se- 
ñor" (Astrana Marín), "Yo no pienso nada, Milord" (Gutiérrez) y "No pienso nada, señor" (González Padilla).

Hamlet no cesa en su ataque. Hay en el personaje una voluntad de acoso expresada en cada una de sus frases. Ahora se lanza a fondo, pues comenta: "¡Linda idea la de reposar entre las piernas de una doncella!" (Astrana Marín), que nada oculta de sus intenciones. Nada oculta en la versión de Gutiérrez: "Pues es una linda idea yacer entre las piernas de una doncella". Y la versión de González Padilla: "Dulce es pensar a los pies de una dama". Pero un momento, aquí tenemos una contradicción absoluta entre esta versión y las dos anteriores. Es indispensable recurrir al inglés: "That's a fair thought to lie between maids' legs". Es claro que los dos primeros traductores han seguido la línea ideológica del original, mientras que la tercera versión se ha desviado de ella considerablemente.

Si la examinamos, pronto deduciremos que nos ha insertado en un mundo de amor cortesano, cuando las relaciones entre la amada y el caballero tenían mucho de platónicas. Pero el desarrollo lógico de la conversación sostenida por Hamlet y Ofelia obliga a rechazar la versión de González Padilla, pues intercala una isla de buenos modales en lo que venía siendo un hostigamiento absoluto a la pobre doncella, además de que interrumpe el fluir de esa lógica y su continuación en las líneas subsecuentes. Si buscamos razones a tal decisión de la traductora, no podemos aceptar las de un error de interpretación, pues en el resto de la obra González Padilla ha demostrado su buen conocimiento del idioma y de la cultura isabelinos. ¿Estaremos ante un caso de censura inconsciente? Y digo inconsciente porque en lo que llevo examinado del diálogo la traductora no esquivó las insinuaciones sexuales de las palabras de Hamlet $\mathrm{y}$, en lo que resta del diálogo, tampoco las esquiva, bien que algo las suavice. ¿Encontró González Padilla demasiado explícito lo dicho, a diferencia del mayor ocultamiento impuesto a lo antes expresado? De ser así, estaríamos ante un ejemplo de censura consciente, inadmisible en cuestiones de traducción. El pacto implícito entre traductor y lector obliga a una honradez extrema en la interpretación de un texto; a igual honradez obliga el otro pacto implícito, aquel entre el traductor y el autor. $\mathrm{O}$ se sigue a éste en sus mandatos o no se lo traduce.

Ofelia se hace la desentendida preguntando: “QQué decís, señor?" (Astrana Marín), “¿Qué cosa, Milord?” (Gutiérrez) y "¿Qué decís, señor?" (González Padilla). La respuesta de Hamlet es sencilla: "Nada" en los tres casos. Pero ¿podría ser todo así de sencillo en Shakespeare? Recurro una vez más a Harold Jenkins: En tiempos del autor "nothing" significa la ausencia de algo y, en idioma popular, se aludía a la virginidad de una 
mujer. Por otro lado, "no thing" pudiera referirse al sexo del hombre. Entonces, acaso en otra versión Ofelia pudiera decir "¿A qué os referís, señor?" y Hamlet responder "A cosa alguna". Como se ve, traducir no es siempre cuestión del sentido directo y sí de las maliciosas connotaciones introducidas por un autor.

En el texto viene un intermedio respecto a la línea de diálogo que estoy explorando, pues la atención de los personajes se centra en la obra representada, cuyo comentario hace Hamlet a tal grado que Ofelia subraya: "Representáis perfectamente el papel de coro, señor" (Astrana Marín), o bien "Sois tan bueno como un coro, Milord" (Gutiérrez), o bien "Sois una especie de coro, señor" (González Padilla), donde la versión de Gutiérrez es la más próxima al original, si bien nada grave ha ocurrido en las otras. Hamlet no desaprovecha para volver a lo suyo, que es incomodar a la joven: "Podría hacer de intérprete entre vos y vuestro amante con sólo que os viera retozar en la escena como títeres" (Astrana Marín), que en voz de Gutiérrez queda en: "Podría servir de intérprete entre tú y tu amante, con sólo que pudiera ver las marionetas retozando", para expresar así en González Padilla: "Podría servir de intérprete entre tu enamorado y tú con tal de poder veros como títeres retozar en la escena", donde "enamorado" suaviza la imagen respecto a las dos versiones anteriores.

¿Por qué dirá en ese momento Ofelia "iQué agudo sois, señor, qué agudo!" (Astrana Marín), "Sois agudo milord, sois agudo" (Gutiérrez) y "¡Qué agudo sois, señor, qué agudo!" (Gonzáles Padilla), abriendo las puertas a un nuevo embate de Hamlet? Incluso sin conocer el inglés se palpa que ese "agudo" de la joven provocará una impertinencia sexual. $Y$ la provoca. La impertinencia se difumina un tanto en la versión de Astrana Marín, que limita la respuesta del príncipe a "Con un suspiro embotaríais mi punta", donde "suspiro" nos lleva a un terreno de lo espiritual muy alejado de las intenciones de quien responde. "Te costaría más de un gemido embotarme la punta" dice en opinión de Gutiérrez, y "gemido" ya se acerca mucho al original. "Te costaría un quejido embotarme el filo" apunta González Padilla. La intención sexual es clara en dos de las versiones analizadas, perdiéndose del todo en la de Astrana Marín debido a la elección del término "suspiro". Si examinamos el inglés, encontramos lo siguiente: "It would cost you a groaning to take off my edge", y no es de negar que "groaning" es una palabra ingrata al lado de "suspiro" pero incluso de "gemido" o de "quejido", que no son malas equivalencias. Se refiere el término a lo que se pensaba era la reacción tenida por una mujer al perder su virginidad. Volvemos a comprobar que una mala elección, en este caso por el traductor español, desvirtúa la oculta intención del texto. 
¿Qué habrá de responder la pobre Ofelia? Pues “¡Siempre de mal en peor!" nos asegura Astrana Marín; "Todavía mejor y peor" en opinión de Gutiérrez y "Siempre de mal en peor" en González Padilla. Según esto, la joven se queja porque Hamlet arrecia sus embestidas. Cuando habla inglés, Ofelia dice: "Still better, and worse", que parece alejarse de ese "mal en peor" privilegiado en dos de las traducciones. Porque Ofelia ha comentado lo siguiente: Cuanto más agudo sois más objetable es lo que decís. Sucede así que incluso las expresiones inocentes lo son en apariencia, pues llegan cargadas de sentido. De aquí deriva la última expresión de Hamlet que examinaré. A lo anterior el príncipe responde: "Así soléis proceder en la elección de vuestros maridos" (Astrana Marín), "Así confundís a vuestros maridos" propone Gutiérrez, alejándose mucho de lo entendido por el español, y "Como los maridos que mal-tomáis" es la opinión de González Padilla, única que se acerca a uno de los juegos de palabras incluidos en las palabras de Hamlet, quien ha dicho "So you mis-take your husbands", una de cuyas interpretaciones es la propuesta por Gutiérrez. Astrana Marín abunda en palabras dada la brevedad del inglés, y deja escapar uno de los significados. Pensemos que en los casamientos religiosos se acepta la unión para los buenos momentos y los malos, ese "better-worse" de Ofelia en un segundo propósito de significado, que el príncipe aprovecha para lanzar su comentario. Y no olvidemos el guión con que el inglés hace clara la intención.

Elegí de propósito este diálogo entre Ofelia y Hamlet porque venía impregnado de segundas intenciones, y era de ver si los traductores elegidos las habían captado y, entonces, cuál había sido su propuesta, o bien en qué sentido erraron el camino. Como el original viene en prosa, no hubo el problema de la versificación, que otros fragmentos de la obra habrían levantado. Recordemos que Shakespeare recurre a la prosa cuando sus personajes son de extracción baja o cuando carecen de elevación los pensamientos que expresan personajes de mejor situación social. Astrana Marín tradujo en prosa todo Shakespeare, grave error en mi opinión, pero aquí no hay problema con ello. Gutiérrez y Gonzáles Padilla optan en varios momentos por el tuteo, que no parece pertinente dada la condición de trato en una corte y que el texto examinado no parece permitir.

Ya adentrándonos en las versiones examinadas, se diría que la de Joaquín Gutiérrez resolvió con mayor acierto las escabrosidades del diálogo impuesto a Ofelia, ya que González Padilla suavizó el tono y las imágenes en un par de ocasiones y tradujo mal en otra, y lo mismo ocurrió con Astrana Marín. En el comercio que el traductor tiene con un texto le está prohibido violentar las intenciones de éste. Le es necesario sacrificar sus 
sentimientos personales a la procuración de un equivalente lo más próximo al original $o$, en el peor de los casos, lo menos alejado del mismo. $Y$ si las disparidades de creencias son considerables, no embarcarse entonces en una traducción, como ya lo expresé antes. Por otro lado, queda establecida una verdad acaso obvia: en el caso de la traducción de clásicos se vuelve una necesidad incluso mayor el conocer lo más que se pueda de la cultura a la cual dicho escritor pertenece. De otra manera, la versión quedará nadando en la superficie del texto, para desdoro de éste y pérdida de los lectores.

\section{Obras citadas}

Shakespeare, William. 1982. Hamlet. Ed. crítica a cargo de Harold JENKINS. Nueva York: The Arden Shakespeare. Methuen. 574 pp. (de las cuales 159 son de Prólogo).

. 1945. Hamlet. Obras completas. Est. prel., trad. y notas Luis ASTRANA MARÍN. Madrid: Aguilar. 1167-1224.

. 2000. Hamlet. Trad. y notas Enriqueta GonZÁlez Padilla, con la ayuda de Alejandra Luna GuZMán y Adrián MuÑoz García. Pról. de Federico Patán. México: Unam.

1982. Hamlet. Trad. y pról. Joaquín GuTiÉrREZ. San José: Editorial Universidad Estatal a Distancia. 